\title{
ELECTRONIC COMMUNICATIONS AND ENVIRONMENTAL CONTROL SYSTEMS FOR THE SEVERELY DISABLED
}

\author{
By B. Andrews, M.Sc., ${ }^{1}$ S. Miller, ${ }^{1}$ D. Horrocks, Ph.D., ${ }^{2}$ J. O. N. Jibowu, B.Sc. ${ }^{2}$ \\ and J. C. ChaWLa, M.D., F.R.C.S. ${ }^{3}$ \\ ${ }^{1}$ Bio Engineering Unit, Department of Medical Physics, University Hospital of Wales, \\ Cardiff, ${ }^{2}$ Department of Electrical Engineering, University College, Cardiff, ${ }^{3}$ Rookwood \\ Hospital, Cardiff
}

\begin{abstract}
A wireless environmental controller is described. The controller can either be used by itself or with other systems. It is suggested that commercially available personal computers, for environmental control and communication, will enable the severely disabled to lead a more independent life and may provide useful mental recreation.
\end{abstract}

Key words: Wireless environmental controller.

ThIs short communication outlines some recent developments at Rookwood using Environmental Control and Personal Computers to improve the independence of the high level spinal injured.

\section{Environment Control}

An electrical appliance controller providing a wireless multi-channel power control system is described. The system is designed to stand alone or to be a computer peripheral. The system consists of transmitter control unit and remote switching and the circuit schematic is shown in Fig. I. Appliances are plugged

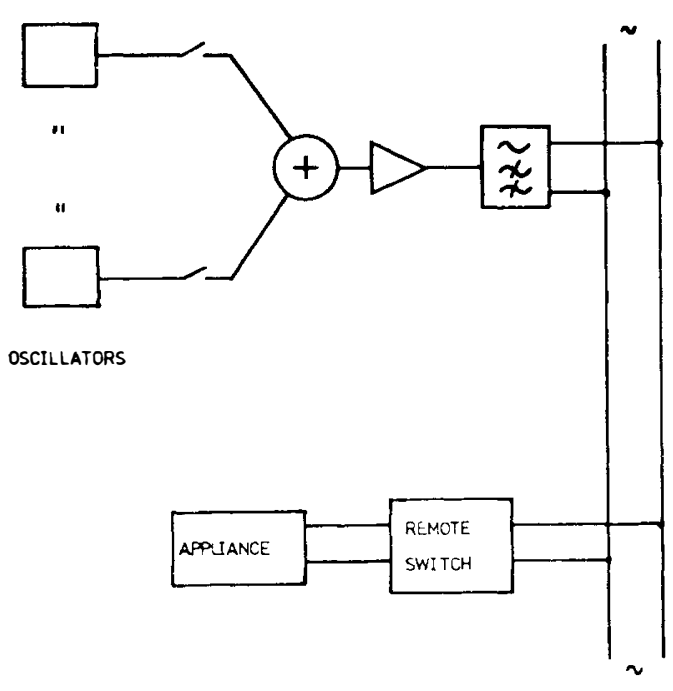

FIG. I

System schematic.

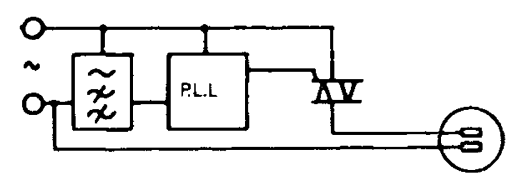

(a)

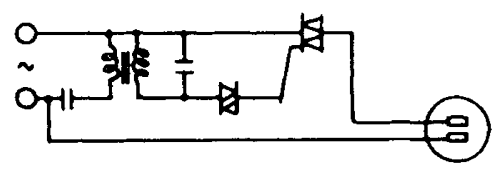

(b)

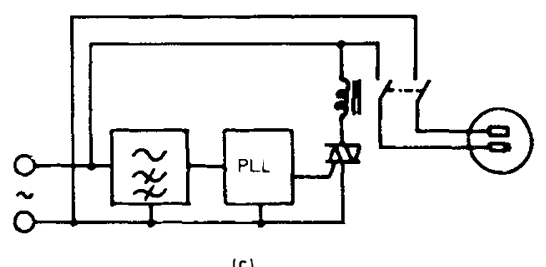

FIG. 2

Remote switch circuits. 
into a remote switch module which may then be plugged into a mains outlet socket. The remote switches are activated by a set of high frequency sinusoidal signals transmitted along the mains wiring. Each remote switch responds only to its own predetermined tone. The tones $(20-600 \mathrm{kc} / \mathrm{s})$ are generated by a set of oscillators within the transmitter control unit. To activate a remote switch the appropriate oscillator is connected to the driver/mains coupler through a mixer stage. The operational range of the system depends upon driver power, sensitivity of the remote and the mains ring arrangement. The system permits control throughout the house and outlying buildings or neighbour's house.

\section{Technical Details}

The remote switch has been developed in three forms illustrated by the circuits schematics in Fig. 2. The simplest switch (Fig. 2b) uses a tuned band pass mains coupling circuit. The switching threshold is set by the diac (or series zenner diodes). Only a limited number of independent channels are feasible, typically three, because the driver must provide sufficient signal power to switch the sensitive gate triac as well as overcome the propagation losses in the mains wiring. The number of channels is also limited by the low $Q$ factor of the tuned circuit. The switch system (Fig. 2a) uses a Phase Locked Loop (PLL) that provides an output level when locked to the incoming signal and also provides a demodulated output. The latter is useful when incorporating a frequencymodulated voice intercom. additional to the on/off control using the same circuitry. Figure $2 \mathrm{c}$ shows a similar system with an isolating relay. Using a PLL system allows use of more than 20 channels. We are developing a sub-carrier tone switching PLL system to further increase the number of channels. The PLL remote switch has a fast response time enabling phase control of mains power to be implemented. This may be useful for remotely dimming lights or controlling heating elements.

The switching in of selected oscillators can be simply achieved by a bank of switches as illustrated in Fig. 3 or under computer control or any of the usual selector mechanisms such as possum. The components are physically small and the costs are comparable with savings of installation costs. The advantages of this type of system are:

I. no installation. This would enable equipment to be made immediately available and easily re-circulated;

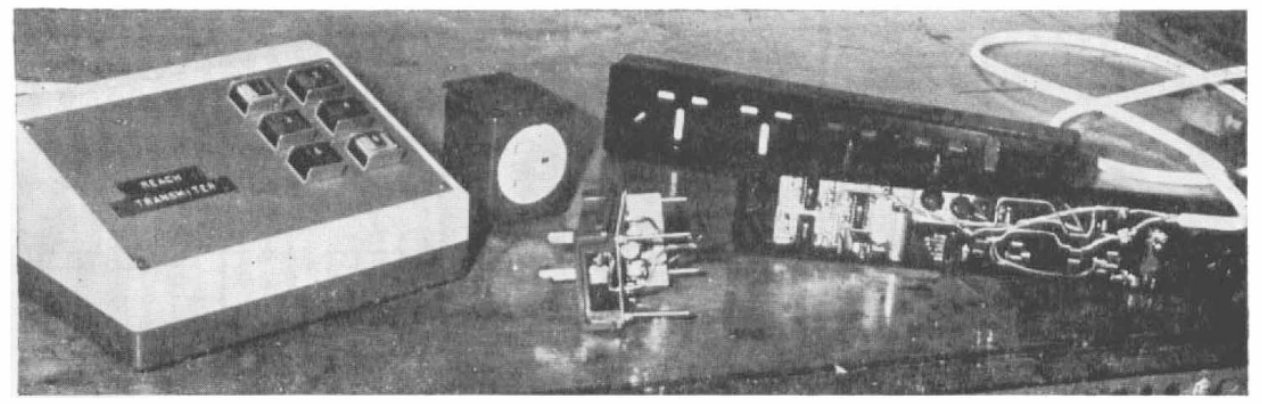

FIG. 3

A six-channel transmitter unit with a single and dual remote mains switch modules. 
2. flexibility in siting and re-positioning the system units;

3. the same mains wiring can be used by more than one user.

\section{Personal Computers}

There are a small number of patients who will require, in addition to typewriter control, the ability to process and manipulate text; some of the requirements may include (a) efficient text composition, (b) text editing, (c) efficient mass storage of text and facilities for rapid review and (d) optional hard copy. A digital computer system is appropriate for such tasks. The personal or home computer is now an economic reality.

There are several such systems commercially available and their number is rapidly increasing. Present costs are typically $\$ 2000$ for a system having a Cathode Ray Tube Video (CRT) display, keyboard, printer and mass storage devices. The price of such systems is highly likely to fall considerably in the near future when some of the larger companies become involved.

These computers have a keyboard as their standard data entry device. These keyboards are often suitable for mouthstick operation, Fig. 4. It may be necessary to devise ways around any double key control operations, e.g. shift key when not lockable. This may be done by modifying the system software slightly or by fitting a mechanical locking mechanism or refitting a lockable switch. Cassette deck keys may be operated by mouthstick directly or by attaching extension pieces to the keys if they are stiff. The Record key can be bypassed by fitting a press button switch or by having a mechanical link to the play key. Single key operation cassette decks are commercially available. Picking up and positioning cassettes may be achieved by having a wire hook attachment on the end of a mouthstick that hooks the cassette through the capstan holes near the top front edge.

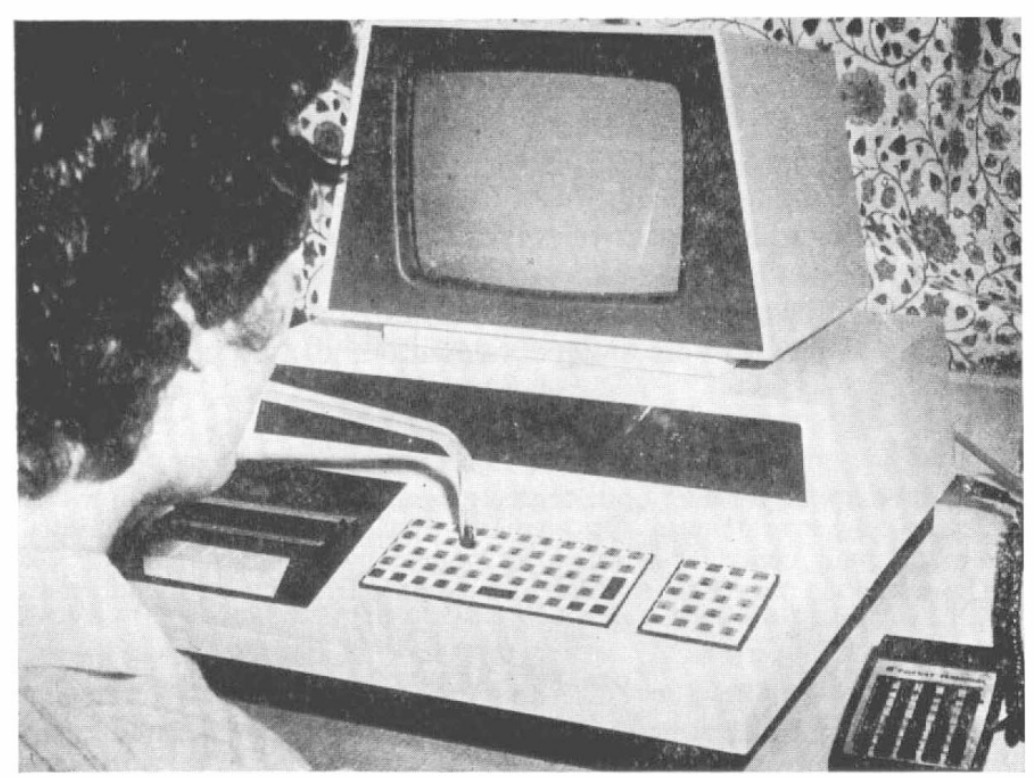

FIG. 4

A tetraplegic patient using a commercially available personal computer. 
The text processing features already listed are programmes usually available from the machine manufacturer as standard options or from user clubs, software dealers or published material in Journals, such as Byte.

Mention here is made to some of our current short projects aimed at providing useful additions to a personal computer.

A pneumatic switch may be used by those to whom a keyboard is unsuited. The switch can be used to control a moveable cursor on the CRT display to enable selection from an array of options. One method we have found convenient is to arrange the options in lines at the bottom of the CRT. A programme controllable cursor is arranged so that it can move along the lines in both directions. The cursor can move one step at a time in each direction under users control and if the control signal is maintained in one direction for pre-set time the cursor automatically steps along at a pre-determined rate. When the control is removed, single step operation is resumed. When the cursor is in the correct position, a further signal is used to make the selection. Typical access time for composing text was $2 \cdot 5$ seconds per character.

A directory programme for cassette tape recordings stores information concerning a recording by asking the user to give the date, the cassette number and side, the stop and start numbers on the digital tape counter and a short description of the recording, together with a classified title. The programme can then upon request list these details for any cassette or for any classification title.

Software is becoming available for these computers dealing with such topics as accounts, record keeping, address directories, calendars, mathematics and statistical packages and games. The personal computer enables the user the option of programming his machine and developing his own software, for some this can provide a useful mental stimulating recreation.

There is clearly a need to identify the user's immediate and future requirements, which in turn will depend upon his aspirations so that a satisfactory match can be suggested with what is available.

We have assessed one patient who has a complete tetraplegia at $\mathrm{C}_{3}$ level. A suitable commercial system, as illustrated in Fig. 4, is being considered for him.

\section{SUMMARY}

A wireless environmental controller is described. The controller can either be used by itself or with other systems. It is suggested that commercially available personal computers, for environmental control and communication, will enable the severely disabled to lead a more independent life and may provide useful mental recreation.

\section{RÉSUMÉ}

Le sujet est un appareil sans fil qui contrôle le milieu. On peut utiliser le contrôleur, sans ou avec des autres systèmes. On suggère que les calculateurs individus, en vente commercialement, pour contrôler le milieu et pour communiquer, rendront les invalides capables de faire une vie plus indépendante et peuvent offrir de la stimulation mentale.

\section{ZUSAMMENFASSUNG}

Ein drahtloser Kontrolapparat wird beschriben. Der Apparat kann entweder allein oder in Verbindung mit anderen Systemen gebraucht werden. Es wird vorgeschlagen, dass kommerziell erhältliche, für Umgebungsregelung und Kommunikation bestimmte Personalcomputers den Schwerbehinderten helfen, ein selbständigeres Leben zu führen, und dass sie nützliche Geistesauffrischung durch sie erhalten können. 